\title{
Osmotic Lysis of Mycoplasma
}

\author{
By S. RAZIN \\ Department of Clinical Microbiology, Hebrew University- \\ Hadassah Medical School, Jerusalem, Israel
}

(Received 7 August 1963)

\section{SUMMARY}

Various Mycoplasma strains were found to differ in their sensitivity to osmotic lysis. Three strains of the saprophytic Mycoplasma laidlawii and a strain of the parasitic $M$. bovigenitalium were readily lysed in media of low tonicity. Strains of the parasitic M. mycoides var. mycoides, M. mycoides var. capri, $M$. gallisepticum and $\boldsymbol{M}$. neurolyticum were to a great extent resistant to osmotic lysis. The sensitivity of $\boldsymbol{M}$. laidlawii and $\boldsymbol{M}$. bovigenitalium to osmotic lysis markedly decreased with ageing of the organisms. $M$. laidlawii was more sensitive to lysis when grown in cholesterol-free media.

\section{INTRODUCTION}

The susceptibility to osmotic lysis of several Mycoplasma strains, bacterial protoplasts, spheroplasts and L-forms was recently compared (Razin \& Argaman, 1963). The mycoplasmas and L-forms were much more resistant to lysis by osmotic shock than were the bacterial protoplasts and spheroplasts. The aim of the present investigation was to test the sensitivity to osmotic lysis of a larger series of Mycoplasma strains and to study the factors which influence their osmotic fragility. Under certain conditions several Mycoplasma strains were found to lyse quantitatively by osmotic shock, yielding a convenient method for the isolation of cell membranes and for obtaining cell-free extracts.

\section{METHODS}

Organisms. Mycoplasma laidlawii strain A (PG8), M. laidlarvii strain B (PG9), $M$. bovigenitalium (PG 11), M. mycoides var. mycoides ( $\mathrm{PG} 1$ ) and $M$. neurolyticum (PG 28) were obtained from Dr D. G. ff. Edward (Wellcome Research Laboratories, Beckenham, Kent, England). M. mycoides var. capri was the gift of Dr E. Klieneberger-Nobel (The Lister Institute for Preventive Medicine, London). M. gallisepticum was obtained from Mrs Ruth Bernstein (Faculty of Agriculture, The Hebrew University, Rehovoth, Israel). A strain which culturally and biochemically resembled $M$. laidlawii was isolated from the oral cavity of a healthy subject (Razin, Michmann \& Shimshoni, 1964); this is referred to as the oral strain.

Suspensions of organisms. The organisms were grown in a modified liquid Edward (1947) medium, which consisted (per 1.) of: Bacto-heart infusion broth, $12 \mathrm{~g}$.; Bacto-peptone, 5 g.; Bacto-yeast extract, 5 g.; glucose, 5 g.; sodium chloride, $2 \cdot 5$ g; $\mathrm{K}_{2} \mathrm{HPO}_{4}, 1 \cdot 7 \mathrm{~g}$.; sodium deoxyribonucleate, 0.02 g.; Bacto-PPLO serum fraction, $20 \mathrm{ml}$.; thallium acetate, $\mathbf{0 \cdot 2 5} \mathrm{g}$.; penicillin G (crystalline), 300,000 units. The 
medium was adjusted to $\mathrm{pH} 8 \cdot 0$. Growth was in 1-2 l. volumes of medium in Erlenmeyer flasks incubated statically at $37^{\circ}$. The organisms were harvested when the optical density of cultures was still increasing. The organisms were sedimented by centrifugation at $9000 \mathrm{~g}$ for $10 \mathrm{~min}$., washed twice in $0.25 \mathrm{M}-\mathrm{NaCl}$ solution and resuspended in the same solution.

Examination of lysis. Test tubes contained $4 \mathrm{ml}$. of serial twofold dilutions of a $0.25 \mathrm{M}-\mathrm{NaCl}$ solution. Each tube received $0 \cdot 1 \mathrm{ml}$. of suspension. The optical density (OD) at $500 \mathrm{~m} \mu$ was measured after incubation for $\mathbf{3 0} \mathrm{min}$. at room temperature (about $20^{\circ}$ ) in a Unicam SP 500 spectrophotometer. The suspensions were then centrifuged at $20,000 \mathrm{~g}$ for $10 \mathrm{~min}$. and the optical density of the clear supernatant fluids was measured at $260 \mathrm{~m} \mu$. Lysis of organisms suspended in solutions of different salt concentrations was examined by phase-contrast microscopy, with a Wild M20 microscope. Suspensions prepared in the lowest $\mathrm{NaCl}$ concentration $(0.006 \mathrm{M})$ were also examined by electron microscopy. Samples of the suspensions were placed on grids covered with collodion films and fixed by $\mathrm{OsO}_{4}$ vapour for $10 \mathrm{~min}$. The specimens were shadowed with a gold-palladium alloy at an angle of $15^{\circ}$ and examined with an RCA EMU 3c electron microscope.

\section{RESULTS}

Sensitivity of Mycoplasma strains to osmotic lysis. The sensitivity of eight Mycoplasma strains to lysis in hypotonic media was measured by optical density changes of suspensions prepared in graded $\mathrm{NaCl}$ solutions (Fig. 1). All three strains of the saprophytic Mycoplasma laidlawii readily lysed in dilute $\mathrm{NaCl}$ solutions, as shown by the marked decrease in the turbidity of the suspensions (OD readings at $500 \mathrm{~m} \mu$ ) and by release of cell constituents which absorbed at $260 \mathrm{~m} \mu$ (Fig. 1a). Of the five parasitic Mycoplasma strains tested, only $\boldsymbol{M}$. bovigenitalium showed a marked tendency to lyse in low-tonicity media (Fig. 1 $a$ ). The other parasitic strains, under the test conditions, were practically resistant to osmotic lysis (Fig. 1b). M. mycoides var. capri differed from all other strains in releasing larger quantities of materials which absorbed at $260 \mathrm{~m} \mu$ at higher salt concentrations. The nature of this phenomenon is now under investigation.

Support for the use of turbidity changes and release of intracellular constituents as parameters for cell lysis was obtained by phase-contrast and electron microscopy. Mycoplasma laidlawii and $M$. bovigenitalium organisms suspended in $\mathbf{0} \cdot 25 \mathrm{M}-\mathrm{NaCl}$ solution were arranged largely in clusters. The organisms were small and contained dense areas. $\mathrm{By}$ decreasing the concentration of $\mathrm{NaCl}$ the clusters disaggregated and the organisms became swollen and less optically dense. The number of organisms in the suspension decreased with decrease of the salt concentration. At the lowest $\mathrm{NaCl}$ concentration $(0.006 \mathrm{M})$ only a few swollen organisms remained and transparent ghosts were seen. In electron micrographs of suspensions of $\boldsymbol{M}$. laidlawii and $M$. bovigenitalium, prepared in $0.006 \mathrm{M}-\mathrm{NaCl}$, only very thin cell membranes were seen (cf. fig. 1 in Razin, 1963). Examination with the phase-contrast microscope of suspensions of the parasitic mycoplasmas which resisted osmotic lysis merely showed some swelling of the organisms in the dilute $\mathrm{NaCl}$ solutions, but no significant decrease in the number of organisms. Samples of these suspensions examined with the electron microscope were found to consist almost entirely of 
organisms and very few membranes. Experiments to lyse $M$. mycoides var. capri and $\boldsymbol{M}$. mycoides var. mycoides by osmotic shock according to the method of Robrish \& Marr (1962) failed. In these experiments washed mycoplasmas were suspended in $3 \mathrm{M}$-glycerol and transferred to $0.05 \mathrm{M}$-tris buffer. Electron micrographs of suspensions treated in this way showed that only a small proportion of the organisms were lysed and appeared as membranes.
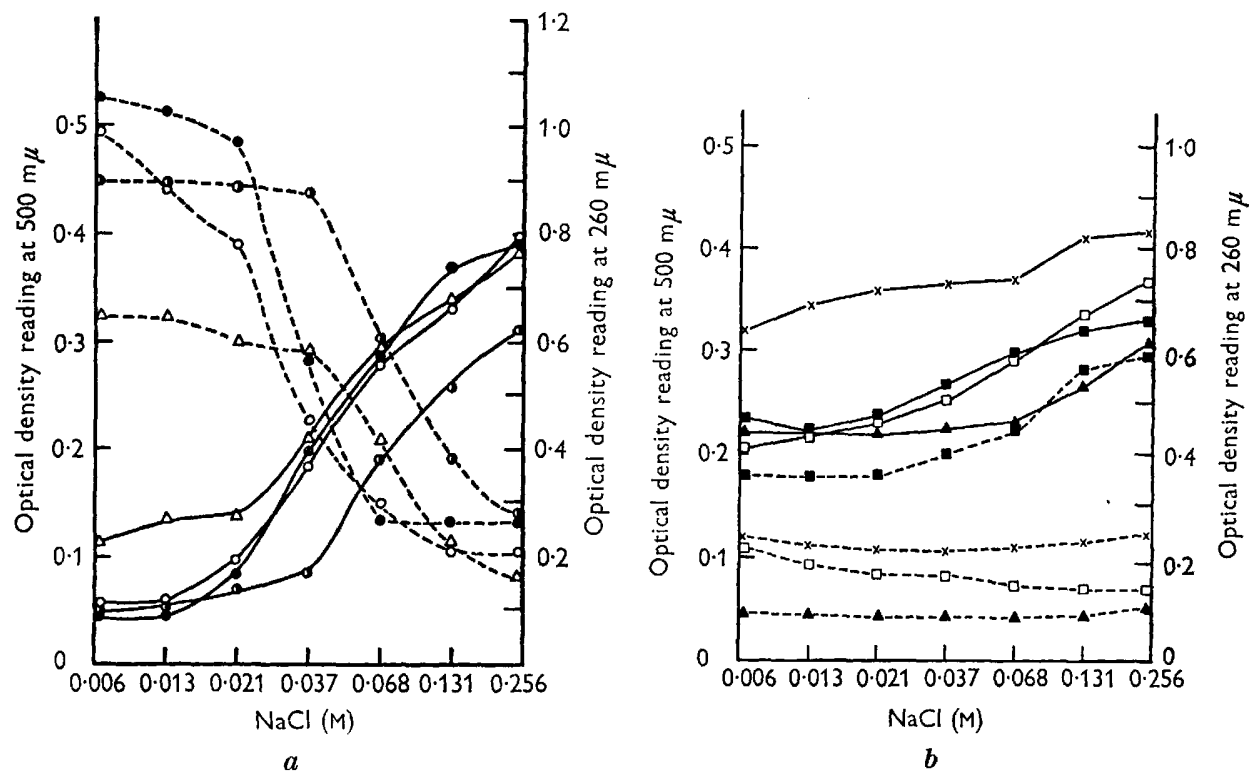

Fig. 1. Sensitivity of Mycoplasma strains to lysis by decreasing the tonicity of the medium. (a) Mycoplasma laidlawii strain A (O); M. laidlawii strain B (O); M. laidlawii oral strain ( ); M. bovigenitalium $(\triangle)$. (b) M. mycoides var. mycoides $(\square) ; M$. mycoides var. capri $(\mathbf{\square}) ; M$. gallisepticum $(\times) ; M$. neurolyticum (A). $--=$ optical density reading at $500 \mathrm{~m} \mu$ of suspensions incubated at room temperature for $30 \mathrm{~min} . ;-\cdots=$ optical density reading at $260 \mathrm{~m} \mu$ of supernatant fluids of corresponding suspensions. The concentration of sodium chloride indicated includes the amount of salt added to the medium with the suspension.

Lysis of cells of different ages. The age of the organisms had a profound effect on their sensitivity to osmotic lysis. The sensitivity of all three Mycoplasma laidlawii strains and of $M$. bovigenitalium to osmotic lysis significantly decreased as the culture grew older (Fig. 2). The organisms were most sensitive to lysis when harvested at the logarithmic phase of growth.

Effect of the growth medium on sensitivity to lysis. Mycoplasma laidlarwii strain A was grown in Edward medium without PPLO serum fraction or in a cholesterolfree synthetic medium (Razin \& Cohen, 1963; Razin \& Rottem, 1964). Organisms grown in these media, and especially when grown in the defined medium, were more sensitive to osmotic lysis than those grown in Edward medium containing PPLO serum fraction (Fig. 3).

\section{DISCUSSION}

Despite the fact that Mycoplasma organisms are limited by a very thin membrane (Razin, 1963) they have been found to be relatively resistant to osmotic shock (Smith \& Sasaki, 1958; Plackett, 1959; Butler \& Knight, 1960; Razin \& Argaman, 
1963); possible explanations for this resistance were discussed by Razin \& Argaman, (1963). The present study, however, has shown that under appropriate conditions Mycoplasma laidlawii and $M$. bovigenitalium may become very sensitive to osmotic lysis. Osmotic lysis was demonstrated only with organisms of an actively-growing culture and in solutions of very low tonicity. The absence of these pre-requisites in previous experiments explains our former failure to notice osmotic lysis of $\boldsymbol{M}$. laidlazwii (Razin \& Argaman, 1963), when the organisms were usually harvested at the stationary or decline phase of growth and suspended in a $\mathrm{M}$-sucrose $+0.05 \mathrm{M}-\mathrm{NaCl}$ solution. To test osmotic fragility $0.1 \mathrm{ml}$. of this suspension was added to $4 \mathrm{ml}$. of de-ionized water, bringing the sucrose concentration to $0.025 \mathrm{M}$, which is sufficient to provide at least partial protection of $\boldsymbol{M}$. laidlawii against osmotic lysis.

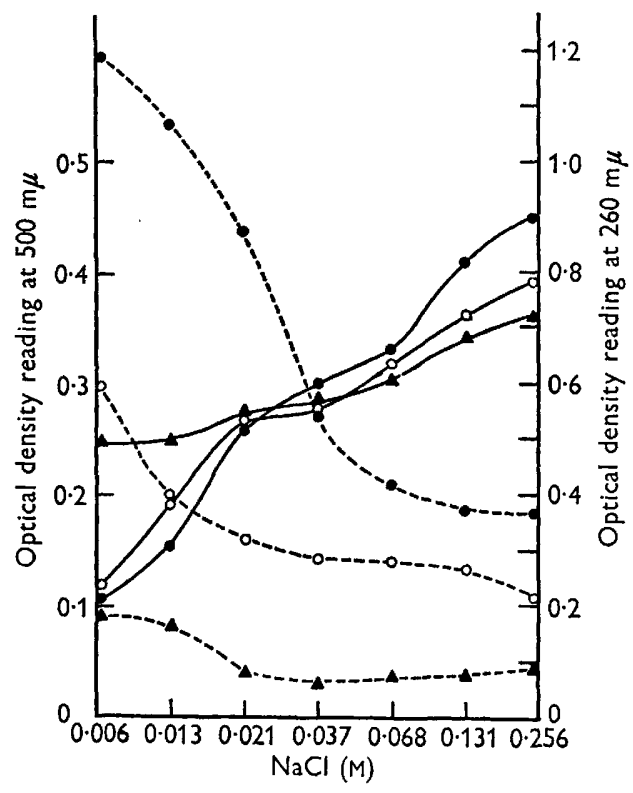

Fig. 2

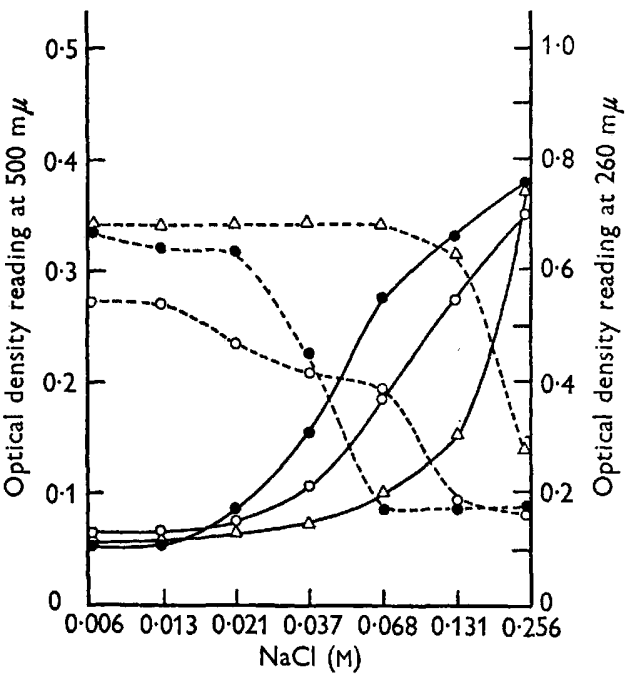

Fig. 3

Fig. 2. Relation of the age of organisms to their sensitivity to osmotic lysis. Organisms of Mycoplasma laidlawii strain B grown in Edward medium for $18 \mathrm{hr}$. (O); $48 \mathrm{hr}$. (O); or $96 \mathrm{hr}$. (A). - - optical density reading at $500 \mathrm{~m} \mu$ of suspensions incubated at room temperature for 30 min.; - . - = optical density reading at $260 \mathrm{~m} \mu$ of the supernatant fluids of the corresponding suspensions.

Fig. 3. Osmotic lysis of Mycoplasma laidlarvii strain A grown in: Edward medium containing $2 \%(v / v)$ PPLO serum fraction (O) ; Edward medium without serum fraction $(O)$; defined medium of Razin \& Cohen, $1963(\triangle) .-=$ optical density reading at $500 \mathrm{~m} \mu$ of suspensions incubated at room temperature for $30 \mathrm{~min}$. ; - . - = optical density reading at $260 \mathrm{~m} \mu$ of the supernatant fluids of the corresponding suspensions.

The main problem arising from the present study is to find an explanation for the marked difference inosmotic fragility among various Mycoplasma strains. The osmotically fragile Mycoplasma laidlawii differs from other mycoplasmas in containing appreciable quantities of carotenoids in its cell membrane (Rothblat \& Smith, 1961; Razin, 1963; Razin, Argaman \& Avigan, 1964). On the other hand, the saprophytic $M$. laidlawii has a much lower cholesterol content than the parasitic mycoplasmas when grown in the same cholesterol-containing medium (Razin, Argaman \& Avigan, 
1964). The amount of cholesterol contained in the cell membrane might possibly determine its tensile strength, since cholesterol is believed to be interspersed between the phospholipid residues in biological membranes and to stabilize their structure (Ponder, 1961). Cholesterol-free $\boldsymbol{M}$. laidlawii organisms grown in the defined medium of Razin \& Cohen (1963) were indeed more susceptible to osmotic lysis than organisms grown in cholesterol-containing media. However, M. laidlawii grown in the defined medium were also deficientin carotenoids, which may likewise act as stabilizers of membrane structure (see Lucy \& Dingle, 1962). The susceptibility of the parasitic $M$. bovigenitalium to osmotic lysis further indicates that the amount of cholesterol in the membrane is not the only factor which determines osmotic fragility since $\boldsymbol{M}$. bovigenitalium membranes have been found to contain at least three times more cholesterol than those of M. laidlawii (Razin, Argaman \& Avigan 1964). The much higher osmotic fragility noted in Mycoplasma organisms in the logarithmic growth phase than in the stationary or decline phase is also known for other bacteria (Mitchell \& Moyle, 1956). This difference in osmotic fragility may be thus due to a higher internal osmotic pressure in mycoplasmas undergoing active growth, or to the presence of weak areas in the membranes of mycoplasmas in active division.

The excellent technical assistance of Mr M. Wormser is gratefully acknowledged.

\section{REFERENCES}

Butler, M. \& KNight, B. C. J. G. (1960). The survival of washed suspensions of Mycoplasma. J. gen. Microbiol. 22, 470.

EDWARD, D. G. ff. (1947). A selective medium for pleuropneumonia-like organisms. J. gen. Microbiol. 1, 238.

Lucy, J. A. \& Dingle, J. T. (1962). Vitamin A and membrane systems. 2. Membrane stability and protein-vitamin A-lipid interactions. Biochem. J. 84, 76P.

Mitchell, P. \& MoYLe, J. (1956). Osmotic function and structure in bacteria, in Bacterial Anatomy, Symp. Soc. gen. Microbiol. 6, 150.

Plackett, P. (1959). On the probable absence of 'mucocomplex' from Mycoplasma mycoides. Biochim. biophys. Acta, 35, 260.

Ponder, E. (1961). The cell membrane and its properties. The Cell. Ed. by J. Brachet and A. E. Mirsky, 2, 2, New York: Academic Press Inc.

Razin, S. (1963). Structure, composition and properties of the PPLO cell envelope. Recent Progress in Microbiology VIII, p. 526. Ed. by N. E. Gibbons. Toronto: University Press.

Razin, S. \& Argaman, M. (1963). Lysis of Mycoplasma, bacterial protoplasts, spheroplasts and L-forms by various agents. J. gen. Microbiol. 30, 155.

Razin, S., Argaman, M. \& Avigan, J. (1964). Chemical composition of Mycoplasma cells and membranes. J. gen. Microbiol. 33, 477 .

Razin, S. \& Cohen, A. (1963). Nutritional requirements and metabolism of Mycoplasma laidlawii. J. gen. Microbiol. 30, 141.

Razin, S., Michmann, J. \& Shimshoni, Z. (1964). The occurrence of Mycoplasma (pleuropneumonia-like organisms, PPLO) in the oral cavity of dentulous and edentulous subjects. J. dent. Res. (in the Press).

Razin, S. \& Rottem, S. (1964). Fatty acid requirements of Mycoplasma laidlawii. J. gen. Microbiol. 32, 4.

Robrish, S. A. \& Marr, A. G. (1962). Location of enzymes in Azotobacter agilis. J. Bact. $83,158$.

Rothblat, G. H. \& Smith, P. F. (1961). Nonsaponifiable lipids of representative pleuropneumonia-like organisms. J. Bact. 82, 479.

SMITH, P. F. \& SASAKI, S. (1958). Stability of pleuropneumonia-like organisms to some physical factors. Appl. Microbiol. 6, 184. 